\title{
Prognostic nomogram for predicting long-term survival in bronchopulmonary carcinoid tumor patients receiving resection
}

\author{
Qiao Li ${ }^{1 \#}$, Qichen Chen ${ }^{2 \#}$, Jinghua Chen ${ }^{2 \#}$, Zijing Wang ${ }^{1}$, Pan Wang $^{3}$, Hong Zhao ${ }^{2}$, Jun Zhao ${ }^{3}$ \\ ${ }^{1}$ Department of Medical Oncology, National Cancer Center/National Clinical Research Center for Cancer/Cancer Hospital, Chinese Academy of \\ Medical Sciences and Peking Union Medical College, Beijing, China; ${ }^{2}$ Department of Hepatobiliary Surgery, National Cancer Center/National \\ Clinical Research Center for Cancer/Cancer Hospital, Chinese Academy of Medical Sciences and Peking Union Medical College, Beijing, China; \\ ${ }^{3}$ Department of Thoracic Surgery, National Cancer Center/National Clinical Research Center for Cancer/Cancer Hospital, Chinese Academy of \\ Medical Sciences and Peking Union Medical College, Beijing, China \\ Contributions: (I) Conception and design: H Zhao, J Zhao, Q Li; (II) Administrative support: H Zhao, J Zhao; (III) Provision of study materials or \\ patients: Q Li, Q Chen, J Chen; (IV) Collection and assembly of data: Z Wang, P Wang; (V) Data analysis and interpretation: Q Chen, J Chen; (VI) \\ Manuscript writing: All authors; (VII) Final approval of manuscript: All authors. \\ "These authors contributed equally to this work. \\ Correspondence to: Hong Zhao. Department of Hepatobiliary Surgery, National Cancer Center/National Clinical Research Center for Cancer/ \\ Cancer Hospital, Chinese Academy of Medical Sciences and Peking Union Medical College, No. 17 Panjiayuan South Lane, Beijing 100021, China. \\ Email: pumczhaohong@126.com; Jun Zhao. Department of Thoracic Surgery, National Cancer Center/National Clinical Research Center for \\ Cancer/Cancer Hospital, Chinese Academy of Medical Sciences and Peking Union Medical College, No. 17 Panjiayuan South Lane, Beijing 100021, \\ China. Email: drzhaojun@126.com.
}

Background: We analyzed bronchopulmonary carcinoid tumor (BPC) patients receiving resection from the Surveillance, Epidemiology, and End Results (SEER) database to identify the predictive factors of their survival. Then, we developed and validated nomograms to predict overall survival (OS) and cancer-specific survival (CSS) in BPC patients.

Methods: BPC patients registered in the SEER database were included. They were divided into a training set and an internal validation set (7:3). BPC patients from our center were included as an external validation set. Independent prognostic factors identified by a Cox regression model in the training set were used to construct nomograms to predict survival. Discrimination and calibration plots were used to evaluate the predictive accuracy of the nomograms. The nomograms were evaluated in both the internal and the external validation datasets.

Results: Age, pathological type, and N stage were identified as independent prognostic factors of OS and CSS by Cox analyses (all $\mathrm{P}<0.05)$. Tumor size $\geq 2.5 \mathrm{~cm}(\mathrm{P}=0.045)$ was an independent factor for unfavorable CSS. Based on these variables, nomograms were constructed. All concordance indexes of the training set, internal validation set, and external validation set indicated that the nomograms had the preferable discriminatory ability. The calibration plots for predictions of the 1-, 3-, and 5-year OS and CSS were in excellent agreement.

Conclusions: Age, pathological type, $\mathrm{N}$ stage, and tumor size were independent predictive factors of prognosis in BPC patients receiving resection. These nomograms could serve as effective and accurate tools for the prognostic evaluation of patients with BPCs.

Keywords: Bronchopulmonary carcinoid (BPC); resection; survival; nomogram; Surveillance, Epidemiology, and End Results (SEER)

Submitted Apr 17, 2021. Accepted for publication Aug 01, 2021.

doi: $10.21037 /$ atm-21-1929

View this article at: https://dx.doi.org/10.21037/atm-21-1929

^ ORCID: 0000-0002-6063-2099. 


\section{Introduction}

Neuroendocrine tumors (NETs) comprise a heterogeneous group of malignancies originating from the diffuse endocrine system that mainly affects the lung and gastrointestinal tract (1). Bronchopulmonary carcinoid tumors (BPCs) are well-differentiated epithelial neuroendocrine neoplasms that represent approximately $25 \%$ of NETs and approximately $1-5 \%$ of all primary lung cancers (2-4). BPCs are the most common pulmonary malignancies diagnosed in children and adolescents. The diagnosis age is generally $45-55$ years old, which is 10 years earlier than other lung malignancies (5).

As BPCs have very different clinical and histological features, they are divided into two subtypes according to differentiation criteria based on the mitotic count, necrosis, and cytologic features $(6,7)$. Typical carcinoids (TCs) are defined as tumors that have fewer than 2 mitoses/ $2 \mathrm{~mm}^{2}$ and an absence of necrosis and atypical carcinoids (ACs) have 2-10 mitoses/2 $\mathrm{mm}^{2}$ and/or foci of punctate necrosis (5). TCs and ACs are low- and intermediategrade lung NETs, respectively, and show different patterns of tumor growth and clinical prognosis (8). TCs are more common than ACs, accounting for $90 \%$ of all BPCs (9). TCs are less invasive, with 5- and 10-year survival rates of $87-100 \%$ and $82-87 \%$. By contrast, ACs are more malignant, with significant reductions in 5- and 10-year survival rates of $50-95 \%$ and $38-75 \%$, respectively (10).

With the improvement of diagnostic techniques and disease awareness, the incidence and prevalence of BPCs have increased by 5-6 times over the last 20-30 years. An increasing number of people are concerned about the treatment and prognosis of BPCs (2). It is widely accepted that surgical resection is the mainstay of treatment for BPCs, but the heterogeneous biological behaviors of BPCs make the prediction of prognosis more challenging. Lymph node involvement present in $5-20 \%$ of cases (11). The tumor-node-metastasis (TNM) classification system was recommended by the North American Neuroendocrine Tumor Society and European Neuroendocrine Tumor Society for the staging of BPCs $(5,12)$. However, it may not be a perfect predictor of lung carcinoid tumor prognosis (13). Previous studies have shown that age, atypical histology, lymph node metastases, and a higher $\mathrm{Ki}-67$ index were independent prognostic predictors of BPCs (9,14-16). However, these factors only predicted the prognosis of BPCs unilaterally. To consider the more comprehensive impact of each factor on prognosis, researchers urgently need to find a more effective prognostic model. Nomograms have been widely used as prognostic tools based on various independent factors to predict the prognoses of numerous malignancies. Chen et al. (17) developed a prognostic nomogram only for ACs. He et al. (18) constructed a nomogram to assess prognosis in patients with BPCs, but they did not perform external validation. There is still a lack of studies on prognostic models for large samples of BPC patients receiving surgical resection.

In the present study, we firstly identified independent prognostic factors in a large cohort and constructed a nomogram to visually predict the overall survival (OS) and cancer-specific survival (CSS) in BPC patients on the basis of the Surveillance, Epidemiology, and End Results (SEER) database. In addition, we performed internal and external validation using SEER database data and a separate inpatient cohort of our hospital, respectively. We present the following article in accordance with the TRIPOD reporting checklist (available at https://dx.doi.org/10.21037/ atm-21-1929).

\section{Methods}

\section{Data source and patient selection}

The data were retrieved from the 18-registry SEER research database [1973-2015] of the National Cancer Institute (19). We identified typical and atypical BPC tumor patients diagnosed between 2010 and 2016 using SEER ${ }^{*}$ Stat software (version 8.3.8). According to the International Classification of Disease for Oncology (3rd ed.) (ICD-O-3) histology codes, 8240 (typical carcinoid) and 8249 (atypical carcinoid) were selected. The following primary site records were involved: C34.0-C34.3, C34.8, and C34.9.

The inclusion criteria were as follows: (I) pathological BPC tumor and (II) receiving surgery. The exclusion criteria were as follows: (I) more than one malignant tumor; (II) pathology of puncture or unknown operation method; (III) survival time $<1$ month; (IV) age $<18$ years; and (V) missing or incomplete patient information. Finally, 2,091 eligible patients diagnosed with lung carcinoid tumors remained (shown in Figure 1). The study was conducted in accordance with the Declaration of Helsinki (as revised in 2013). The study was approved by Institutional Review Board of the Cancer Institute \& Hospital, Chinese Academy of Medical Sciences (ethical approval number: NCC-006062) and informed consent was taken from all the patients. 


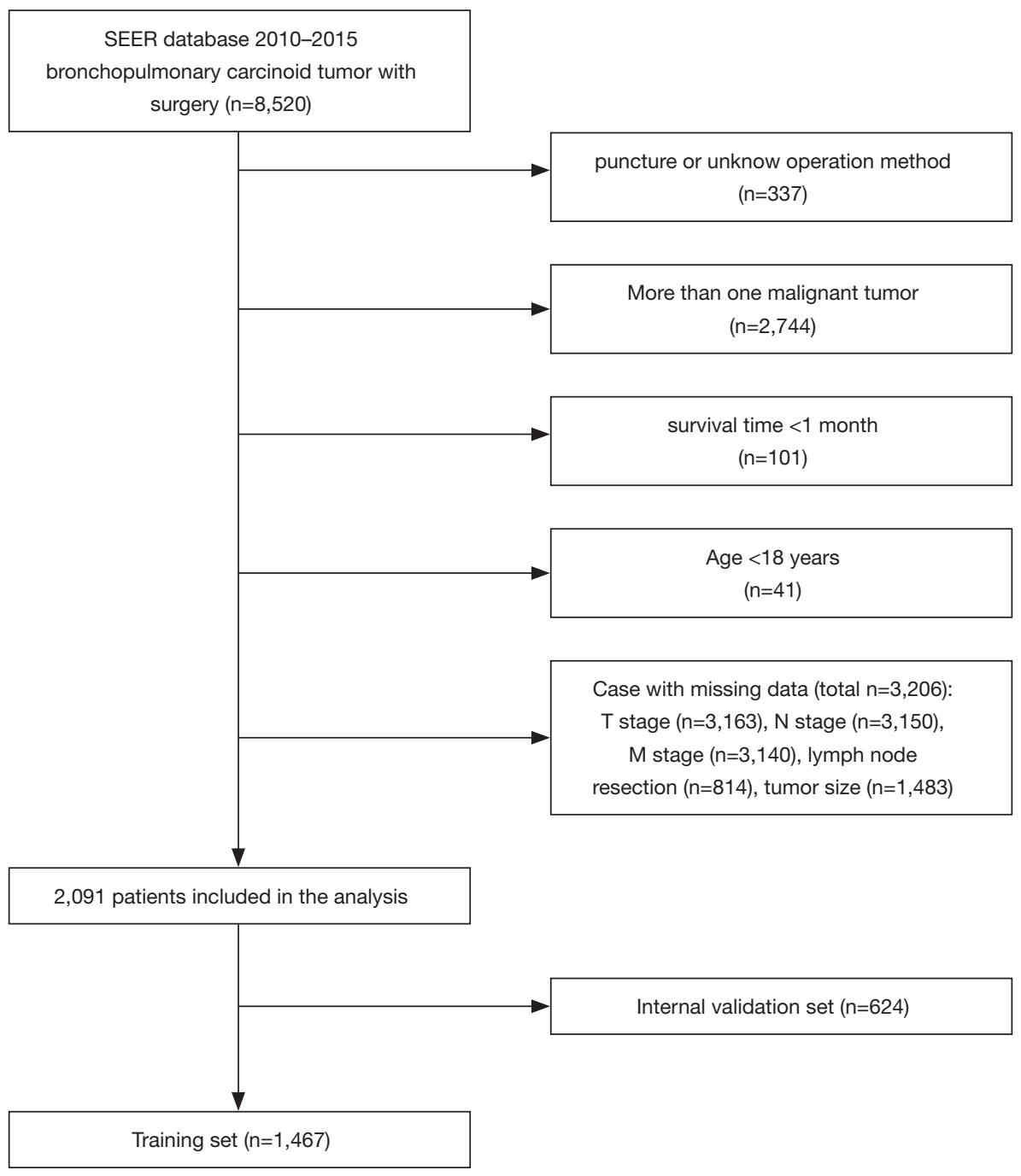

Figure 1 Flow diagram for the selection of bronchopulmonary carcinoid tumors included in the final analyses based on the SEER dataset.

\section{Study design and statistical analyses}

Patient characteristics retrieved from the database included age at diagnosis, sex, race, marital status, histological grade, SEER summary stage, T stage (AJCC, 7 th ed.), N stage (AJCC, 7th ed.), $M$ stage (AJCC, 7th ed.), tumor size, regional nodes examined, and treatment information. OS and CSS were the primary endpoints. OS was defined from the date of diagnosis to death due to any cause. CSS was defined from the date of diagnosis to death due to bronchopulmonary carcinoid tumors. Patients from the SEER database were randomly divided into a training set and an internal validation set $7: 3)$. BPC patients from our center were included as the external validation set.
The chi-square test was used for the comparison of categorical variables, while the Kaplan-Meier method and log-rank test were used for survival analysis. Variables that achieved significance at $\mathrm{P}<0.1$ in univariate Cox regression were entered into multivariate Cox proportional hazard models for further analysis. The hazard ratio (HR) and the associated $95 \%$ confidence interval (CI) were calculated. Statistical analyses to identify the prognostic factors were performed in SPSS 25.0 (IBM Corp, Armonk, NY, USA).

Independent risk factors identified in the multivariate analysis based on the training database were used to construct nomograms to predict survival by using $\mathrm{R}$ version 3.5.1 (http://www.r-project.org/). The nomograms were evaluated in both the internal validation SEER dataset 
and the external validation dataset. $\mathrm{X}$-tile analysis was conducted to determine the optimal segmentation threshold for dividing patients into two subgroups with different prognoses. Calibration plots were used for the comparison between nomogram-predicted and observed survival. The concordance index (C-index) was used for the measurement of the nomogram between the performance and predicted results. A larger C-index revealed more accuracy for prognostic prediction. Differences with $\mathrm{P}<0.05$ (two-sided) were considered statistically significant.

\section{Results}

\section{Patient characteristics}

A total of 8,520 patients diagnosed with BPCs from 2010 to 2016 were screened from the SEER database. After eliminating 6,429 patients based on the exclusion criteria, 2,091 patients with BPCs who underwent resection were included for further analysis (shown in Figure 1). These patients were divided into the training set $(\mathrm{n}=1,467)$ and internal validation set $(\mathrm{n}=624)$. Their baseline demographic, clinical, and pathological features are summarized in Table 1. No significant difference was found between these two sets (all $\mathrm{P}>0.05$ ). Following the inclusion and exclusion criteria above, a total of 172 patients from our center were finally included in our study as the external validation set. The median follow-up times for the training set, internal validation set, and external validation set were 42.0, 39.0, and 58.7 months, respectively.

\section{Independent prognostic factors for OS and CSS}

In the training cohort, the X-tile analysis of CSS was performed using the data of patients in the SEER database to determine the optimal cut-off value for tumor size, and the optimal cut-off value was $2.4 \mathrm{~cm}$ (shown in Figure 2). According to the optimum cut-off points of the above values, patients then were divided into 2 groups (tumor size $<2.5 \mathrm{~cm}$, tumor size $\geq 2.5 \mathrm{~cm}$ ). Univariate and multivariate Cox regression analyses were performed on the training set to evaluate each prognostic factor for OS and CSS. In univariate regression analyses, age, primary site, SEER stage, histology, $\mathrm{N}$ stage, surgery style, and chemotherapy were significantly related to OS (all $\mathrm{P}<0.05$ ). In multivariate Cox regression analyses, age $61-70$ years ( $\mathrm{HR}=2.140,95 \%$ CI: $1.265-3.620, \mathrm{P}=0.005)$, age $>70$ years $(\mathrm{HR}=4.288,95 \%$ CI: $2.581-7.122, \mathrm{P}<0.001)$, atypical carcinoids ( $\mathrm{HR}=2.549$,
95\% CI: $1.547-4.202, \mathrm{P}<0.001)$, N1 stage (HR $=2.082$, 95\% CI: 1.126-3.848, $\mathrm{P}=0.019)$ and $\mathrm{N} 2+\mathrm{N} 3$ stage (HR $=3.279,95 \%$ CI: $1.719-6.255, \mathrm{P}<0.001)$ were identified as independent factors for worse OS (Table 2).

In univariate regression analyses, age, SEER stage, tumor size, histology, $\mathrm{N}$ stage, $\mathrm{M}$ stage, and chemotherapy were significantly related to CSS (all $\mathrm{P}<0.05$ ). In multivariate Cox regression analyses, age $61-70$ years ( $\mathrm{HR}=3.393,95 \%$ CI: $1.423-8.090, \mathrm{P}=0.006)$, age $>70$ years $(\mathrm{HR}=6.321$, 95\% CI: $2.674-14.941, \mathrm{P}<0.001$ ), tumor size $\geq 2.5 \mathrm{~cm}$ (HR $=1.976,95 \%$ CI: $1.015-3.848, \mathrm{P}=0.045$ ), atypical carcinoids $(\mathrm{HR}=3.724,95 \% \mathrm{CI}: 1.803-7.693, \mathrm{P}<0.001), \mathrm{N} 1$ stage (HR $=2.757,95 \%$ CI: $1.136-6.693, \mathrm{P}=0.025)$ and $\mathrm{N} 2+\mathrm{N} 3$ stage $(\mathrm{HR}=5.015,95 \% \mathrm{CI}: 2.111-11.913, \mathrm{P}<0.001)$ were identified as independent factors for worse CSS (Table 3).

\section{Survival outcomes}

The 1-, 3-, and 5-year OS rates of the training set were $97.9 \%, 94.7 \%$, and $91.5 \%$, respectively. The $1-, 3-$, and 5 -year OS rates of the internal validation set were $98.9 \%$, $96.0 \%$, and $92.3 \%$, respectively. The 1-, 3-, and 5-year OS rates of the external validation set were $99.3 \%, 95.7 \%$, and $92.9 \%$, respectively. Subgroup survival analyses of independent prognostic factors identified above, including age, histology, and $\mathrm{N}$ stage, were conducted based on Kaplan-Meier analysis with the log-rank test in the training set (shown in Figure 3). Patients aged $>70$ years had significantly worse OS than patients aged $61-70$ years and patients aged $\leq 60$ years. Differences between any two groups were significant for the OS comparisons (age $\leq 60$ years $v$ s. age $61-70$ years, $\mathrm{P}=0.004$; age $\leq 60$ years $v s$. age $>70$ years, $\mathrm{P}<0.001$; age $61-70$ years $v$ s. age $>70$ years, $\mathrm{P}=0.008)$. ACs were significantly associated with worse OS $(\mathrm{P}<0.001)$. Patients with the N0 stage had significantly better OS than patients with the $\mathrm{N} 1$ stage and patients with the $\mathrm{N} 2+\mathrm{N} 3$ stage $(\mathrm{P}<0.001)$.

The 1-, 3-, and 5-year CSS rates of the training set were $99.2 \%, 97.9 \%$, and $96.3 \%$, respectively. The 1-, 3-, and 5 -year CSS rates of the internal validation set were $99.5 \%, 98.6 \%$, and $96.4 \%$, respectively. Subgroup survival analyses of independent prognostic factors identified above, including age, tumor size, histology, and $\mathrm{N}$ stage, were conducted based on Kaplan-Meier analysis with the log-rank test in the training set (shown in Figure 4). The patients aged $\leq 60$ years had significantly better CSS than patients with age 61-70 years and patients with age $>70$ years $(\mathrm{P}<0.001)$. Tumor size $\geq 2.5 \mathrm{~cm}$ was associated 
Table 1 The demographic and clinicopathological variables of the bronchopulmonary carcinoid tumor training cohort and external validation cohort

\begin{tabular}{|c|c|c|}
\hline Factor & $\begin{array}{l}\text { Training cohort, } \\
\mathrm{N}=1,467(\%)\end{array}$ & $\begin{array}{l}\text { Validation cohort, } \\
\qquad \mathrm{N}=624(\%)\end{array}$ \\
\hline \multicolumn{3}{|l|}{ Sex } \\
\hline Female & $1,007(68.6)$ & $437(70.0)$ \\
\hline Male & 460 (31.4) & $187(30.0)$ \\
\hline \multicolumn{3}{|l|}{ Age } \\
\hline$\leq 60$ & 753 (51.3) & 327 (52.4) \\
\hline $61-70$ & 437 (29.8) & $180(28.8)$ \\
\hline$>70$ & 277 (18.9) & $117(18.8)$ \\
\hline \multicolumn{3}{|l|}{ Marital status } \\
\hline Unmarried & $616(42.0)$ & $250(40.1)$ \\
\hline Married & $851(58.0)$ & 374 (59.9) \\
\hline \multicolumn{3}{|l|}{ Laterality } \\
\hline Left & $605(41.2)$ & $253(40.5)$ \\
\hline Right + other & $858(58.5)$ & 371 (59.5) \\
\hline \multicolumn{3}{|l|}{ Primary site } \\
\hline Lower lobe & $593(40.4)$ & $271(43.4)$ \\
\hline Middle lobe & $297(20.2)$ & $110(17.6)$ \\
\hline Upper lobe & 469 (32.0) & 199 (31.9) \\
\hline Other & $108(7.4)$ & $44(7.1)$ \\
\hline \multicolumn{3}{|l|}{ SEER stage } \\
\hline Localized & $1,063(72.5)$ & $413(66.2)$ \\
\hline Regional & 317 (21.6) & $165(26.4)$ \\
\hline Distant & $87(5.9)$ & $46(7.4)$ \\
\hline \multicolumn{3}{|l|}{ Tumor size } \\
\hline$<2.5 \mathrm{~cm}$ & $931(63.5)$ & 426 (68.3) \\
\hline$\geq 2.5 \mathrm{~cm}$ & $536(36.5)$ & $198(31.7)$ \\
\hline \multicolumn{3}{|l|}{ Histology } \\
\hline Typical carcinoids & 1,295 (88.3) & 557 (89.3) \\
\hline Atypical carcinoids & $172(11.7)$ & $67(10.7)$ \\
\hline \multicolumn{3}{|l|}{ 7th T stage } \\
\hline $\mathrm{T} 1$ & 942 (64.2) & 402 (64.4) \\
\hline $\mathrm{T} 2$ & $345(23.5)$ & $129(20.7)$ \\
\hline T3 & $125(8.5)$ & $60(9.6)$ \\
\hline T4 & $55(3.8)$ & $33(5.3)$ \\
\hline
\end{tabular}

Table 1 (continued)
Table 1 (continued)

\begin{tabular}{|c|c|c|}
\hline Factor & $\begin{array}{l}\text { Training cohort, } \\
\mathrm{N}=1,467(\%)\end{array}$ & $\begin{array}{l}\text { Validation cohort, } \\
\qquad \mathrm{N}=624(\%)\end{array}$ \\
\hline \multicolumn{3}{|l|}{ 7th $\mathrm{N}$ stage } \\
\hline No & $1,280(87.3)$ & $541(86.7)$ \\
\hline $\mathrm{N} 1$ & $119(8.1)$ & $56(9.0)$ \\
\hline $\mathrm{N} 2+\mathrm{N} 3$ & $68(4.6)$ & $27(4.3)$ \\
\hline \multicolumn{3}{|l|}{ 7th M stage } \\
\hline MO & $1,418(96.7)$ & $602(96.5)$ \\
\hline M1 & 49 (3.3) & $22(3.5)$ \\
\hline \multicolumn{3}{|l|}{ Surgery } \\
\hline Wedge resection & $292(19.9)$ & $138(22.1)$ \\
\hline Segmental resection & $67(4.6)$ & $30(4.8)$ \\
\hline Lobectomy & $1,046(71.3)$ & $434(69.6)$ \\
\hline Pneumonectomy & $62(4.2)$ & $22(3.5)$ \\
\hline \multicolumn{3}{|l|}{ Chemotherapy } \\
\hline No/unknown & $1,428(97.3)$ & $600(96.2)$ \\
\hline Yes & $39(2.7)$ & $24(3.8)$ \\
\hline \multicolumn{3}{|l|}{$\begin{array}{l}\text { Regional nodes } \\
\text { examined }\end{array}$} \\
\hline None & $233(15.9)$ & $112(17.9)$ \\
\hline Yes & $1,234(84.1)$ & $512(82.1)$ \\
\hline
\end{tabular}

with worse CSS $(\mathrm{P}=0.001)$. ACs were significantly associated with worse CSS $(\mathrm{P}<0.001)$. Patients with the N0 stage had significantly better OS than patients with the $\mathrm{N} 1$ stage and patients with the $\mathrm{N} 2+\mathrm{N} 3$ stage $(\mathrm{P}<0.001)$. Differences between any two groups were significant for the CSS comparisons (N0 vs. N1, $\mathrm{P}=0.002 ; \mathrm{N} 0$ vs. $\mathrm{N} 2+\mathrm{N} 3$, $\mathrm{P}<0.001 ; \mathrm{N} 1$ vs. $\mathrm{N} 2+\mathrm{N} 3, \mathrm{P}=0.041)$.

\section{Development and validation of the prognostic nomogram for OS and CSS}

The independent prognostic factors above also served as variables to develop the nomogram for OS and CSS (shown in Figure 5). According to the total risk scores and X-tile analysis, the patients were divided into high-risk group and low-risk group. The Kaplan-Meier analysis and log-rank tests were conducted to compared OS and CSS between two groups (shown in Figure 6). Figure $5 A$ showed the 
A

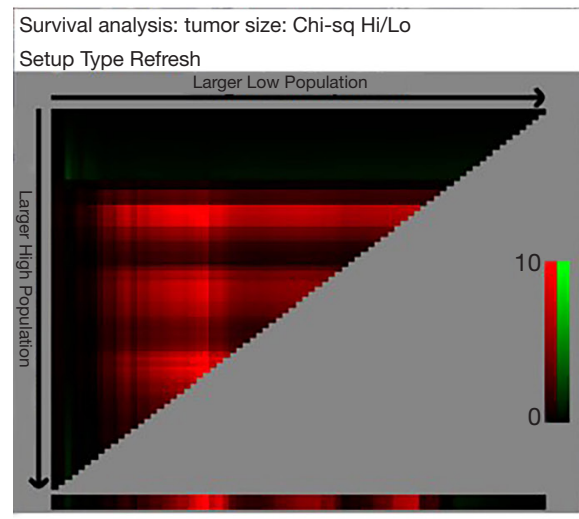

B

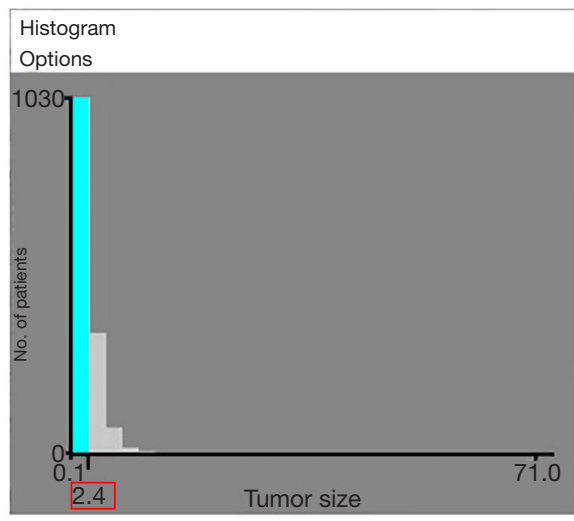

C

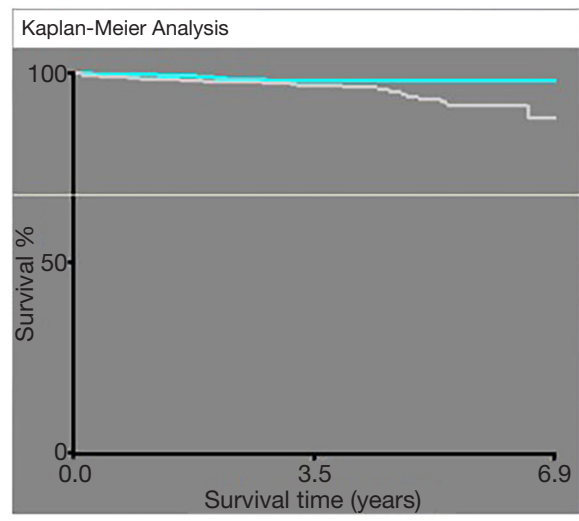

Figure 2 The analysis of the optimal cut-off point for the tumor size by X-tile analysis. (A) The cursor can be manually moved over any coloration of the plot to choose the cut-off point for tumor size (B) to reveal survival curves (C). When the cursor was moved into the horizontal axis, the optimal cut-off point for tumor size was chosen. B. Histogram of the entire cohort divided into tumor size $<2.5 \mathrm{~cm}$ and tumor size $\geq 2.5 \mathrm{~cm}$ subgroups according to the optimal cut-off value of $2.4 \mathrm{~cm}$ by panel A. Blue bars represent the tumor size $<2.5 \mathrm{~cm}$ group, and gray bars represent the tumor size $\geq 2.5 \mathrm{~cm}$. (C) Kaplan-Meier plot of CSS in groups stratified using the optimal cut-off value of tumor size. Blue curves represented the tumor size $<2.5 \mathrm{~cm}$ group, and gray curves represented the tumor size $\geq 2.5 \mathrm{~cm}$ group.

Table 2 Univariate and multivariate analyses of clinicopathological parameters for OS in training cohort

\begin{tabular}{|c|c|c|c|c|}
\hline Factor & \multicolumn{2}{|c|}{ Univariate analysis } & \multicolumn{2}{|c|}{ Multivariate analysis } \\
\hline \multicolumn{5}{|l|}{ Sex } \\
\hline Female & - & Reference & & \\
\hline Male & 0.101 & $1.412(0.935-2.132)$ & & \\
\hline$\leq 60$ & - & Reference & - & Reference \\
\hline $61-70$ & 0.005 & $2.129(1.264-3.587)$ & 0.005 & $2.140(1.265-3.620)$ \\
\hline$>70$ & $<0.001$ & $4.017(2.432-6.637)$ & $<0.001$ & $4.288(2.581-7.122)$ \\
\hline \multicolumn{5}{|l|}{ Marital status } \\
\hline \multicolumn{5}{|l|}{ Laterality } \\
\hline Left & - & Reference & & \\
\hline Right + other & 0.123 & $0.727(0.485-1.090)$ & & \\
\hline \multicolumn{5}{|l|}{ Primary site } \\
\hline Lower lobe & - & Reference & & \\
\hline Middle lobe & 0.012 & $0.416(0.210-0.824)$ & & \\
\hline Upper lobe & 0.291 & $0.783(0.497-1.233)$ & & \\
\hline Other & 0.532 & $0.762(0.326-1.784)$ & & \\
\hline
\end{tabular}

Table 2 (continued) 
Table 2 (continued)

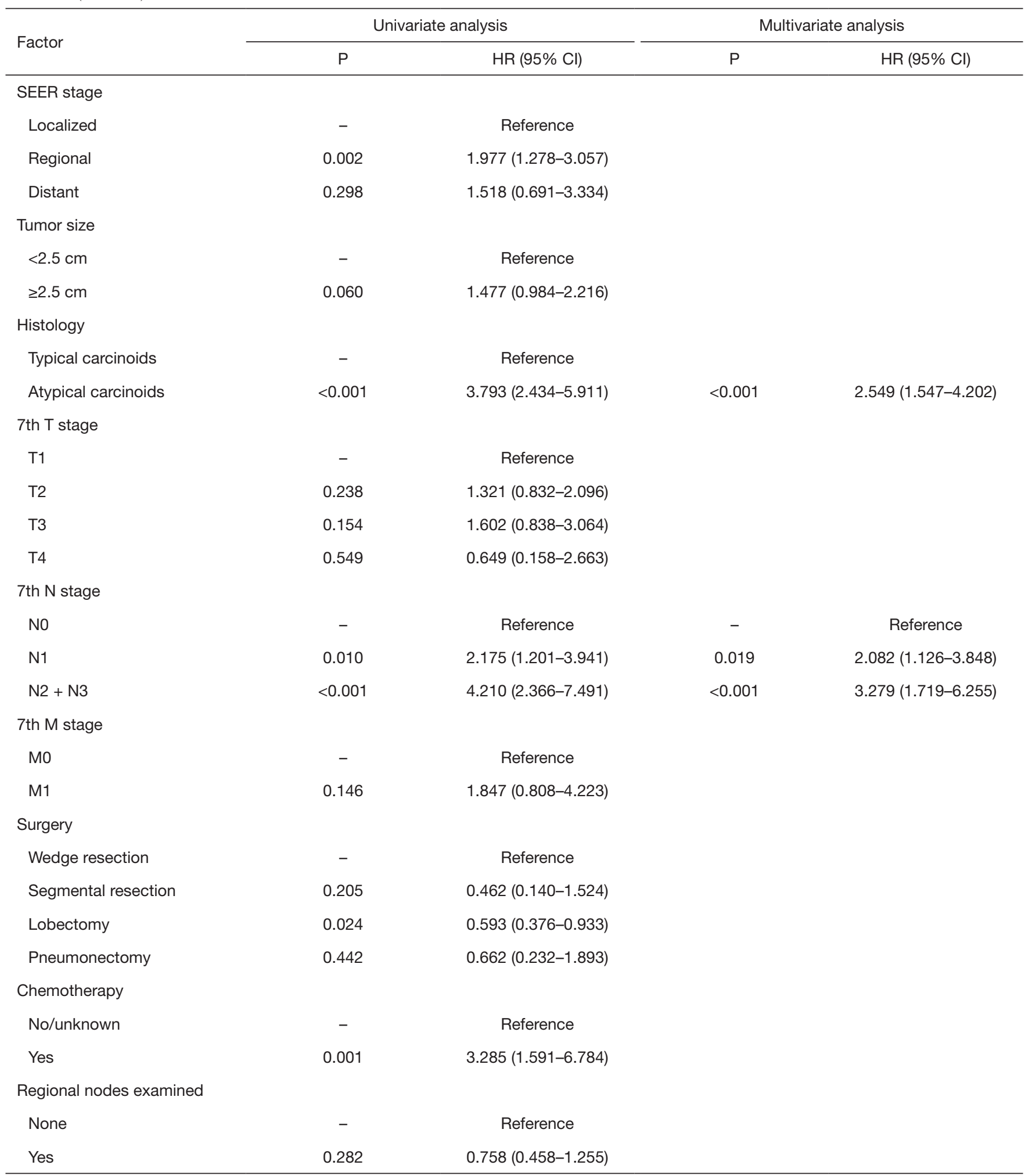

OS, overall survival; HR, hazard ratio; $\mathrm{Cl}$, confidence interval. 
Page 8 of 18

Li et al. Prognostic nomogram of BPC

Table 3 Univariate and multivariate analyses of clinicopathological parameters for CSS in training cohort

\begin{tabular}{|c|c|c|c|c|}
\hline Factor & \multicolumn{2}{|c|}{ Univariate analysis } & \multicolumn{2}{|c|}{ Multivariate analysis } \\
\hline \multicolumn{5}{|l|}{ Sex } \\
\hline Female & - & Reference & & \\
\hline Male & 0.131 & $1.628(0.864-3.065)$ & & \\
\hline$\leq 60$ & - & Reference & - & Reference \\
\hline $61-70$ & 0.006 & 3.360 (1.424-7.927) & 0.006 & 3.393 (1.423-8.090) \\
\hline$>70$ & $<0.001$ & $5.629(2.408-13.161)$ & $<0.001$ & $6.321(2.674-14.941)$ \\
\hline \multicolumn{5}{|l|}{ Marital status } \\
\hline \multicolumn{5}{|l|}{ Laterality } \\
\hline Left & - & Reference & & \\
\hline Right + other & 0.519 & $0.813(0.433-1.526)$ & & \\
\hline \multicolumn{5}{|l|}{ Primary site } \\
\hline Lower lobe & - & Reference & & \\
\hline Middle lobe & 0.331 & $0.608(0.223-1.660)$ & & \\
\hline Upper lobe & 0.498 & 1.267 (0.640-2.508) & & \\
\hline Other & 0.340 & $0.374(0.050-2.821)$ & & \\
\hline \multicolumn{5}{|l|}{ SEER stage } \\
\hline$<2.5 \mathrm{~cm}$ & - & Reference & & \\
\hline$\geq 2.5 \mathrm{~cm}$ & 0.002 & $2.814(1.476-5.364)$ & 0.045 & $1.976(1.015-3.848)$ \\
\hline \multicolumn{5}{|l|}{ Histology } \\
\hline Typical carcinoids & - & Reference & & \\
\hline Atypical carcinoids & $<0.001$ & $7.672(4.076-14.441)$ & $<0.001$ & 3.724 (1.803-7.693) \\
\hline \multicolumn{5}{|l|}{ 7th T stage } \\
\hline $\mathrm{T} 1$ & - & Reference & & \\
\hline T2 & 0.296 & $1.455(0.720-2.942)$ & & \\
\hline T3 & 0.525 & $1.413(0.487-4.102)$ & & \\
\hline T4 & 0.818 & $0.791(0.107-5.866)$ & & \\
\hline
\end{tabular}

Table 3 (continued) 
Table 3 (continued)

\begin{tabular}{|c|c|c|c|c|}
\hline Factor & \multicolumn{2}{|c|}{ Univariate analysis } & \multicolumn{2}{|c|}{ Multivariate analysis } \\
\hline \multicolumn{5}{|l|}{ 7th $\mathrm{N}$ stage } \\
\hline No & - & Reference & - & Reference \\
\hline N1 & 0.003 & 3.578 (1.527-8.383) & 0.025 & $2.757(1.136-6.693)$ \\
\hline \multicolumn{5}{|l|}{ 7th M stage } \\
\hline MO & - & Reference & & \\
\hline M1 & 0.004 & 4.020 (1.572-10.282) & & \\
\hline \multicolumn{5}{|l|}{ Surgery } \\
\hline Lobectomy & 0.245 & $0.660(0.327-1.330)$ & & \\
\hline Pneumonectomy & 0.400 & $0.415(0.054-3.217)$ & & \\
\hline \multicolumn{5}{|l|}{ Chemotherapy } \\
\hline No/unknown & - & Reference & & \\
\hline Yes & $<0.001$ & $6.481(2.714-15.474)$ & & \\
\hline \multicolumn{5}{|c|}{ Regional nodes examined } \\
\hline None & - & Reference & & \\
\hline Yes & 0.766 & $0.883(0.390-2.002)$ & & \\
\hline
\end{tabular}

CSS, cancer-specific survival; HR, hazard ratio; Cl, confidence interval.
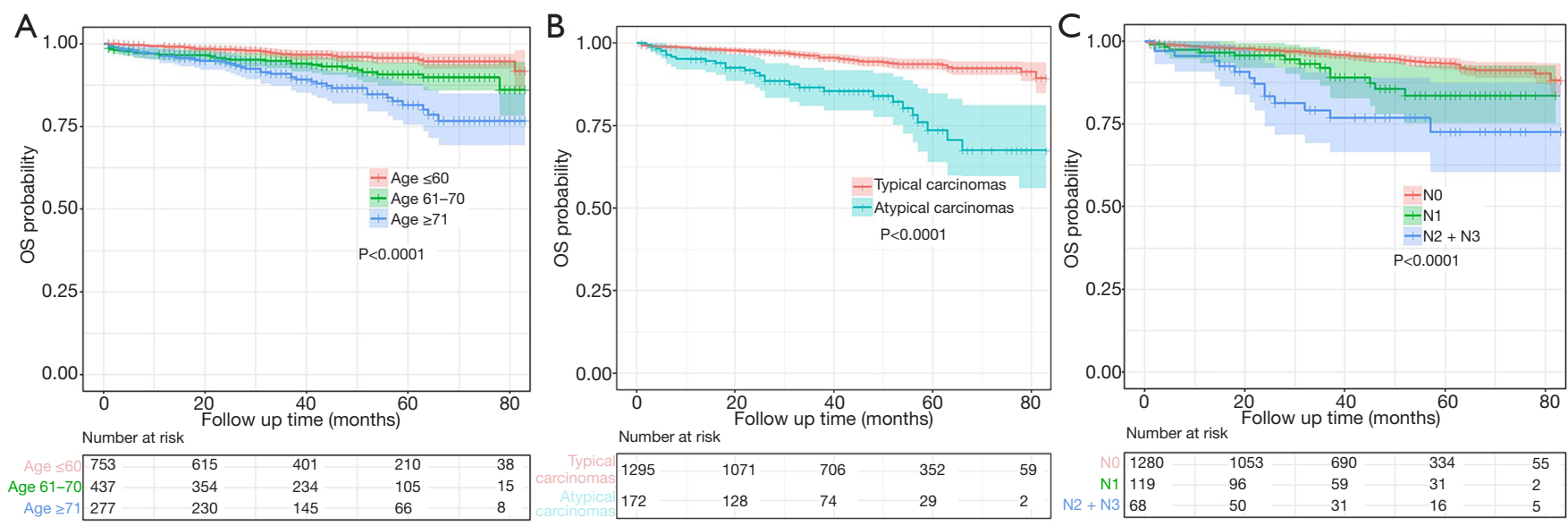

Figure 3 Overall survival analysis. (A) Age $\leq 60$ years $v s$. age $61-70 v s$. age $>70$ years. (B) Typical carcinoids vs. atypical carcinoids. (C) N0 stage $v s$. N1 stage $v s . \mathrm{N} 2+\mathrm{N} 3$ stage. OS, overall survival. 

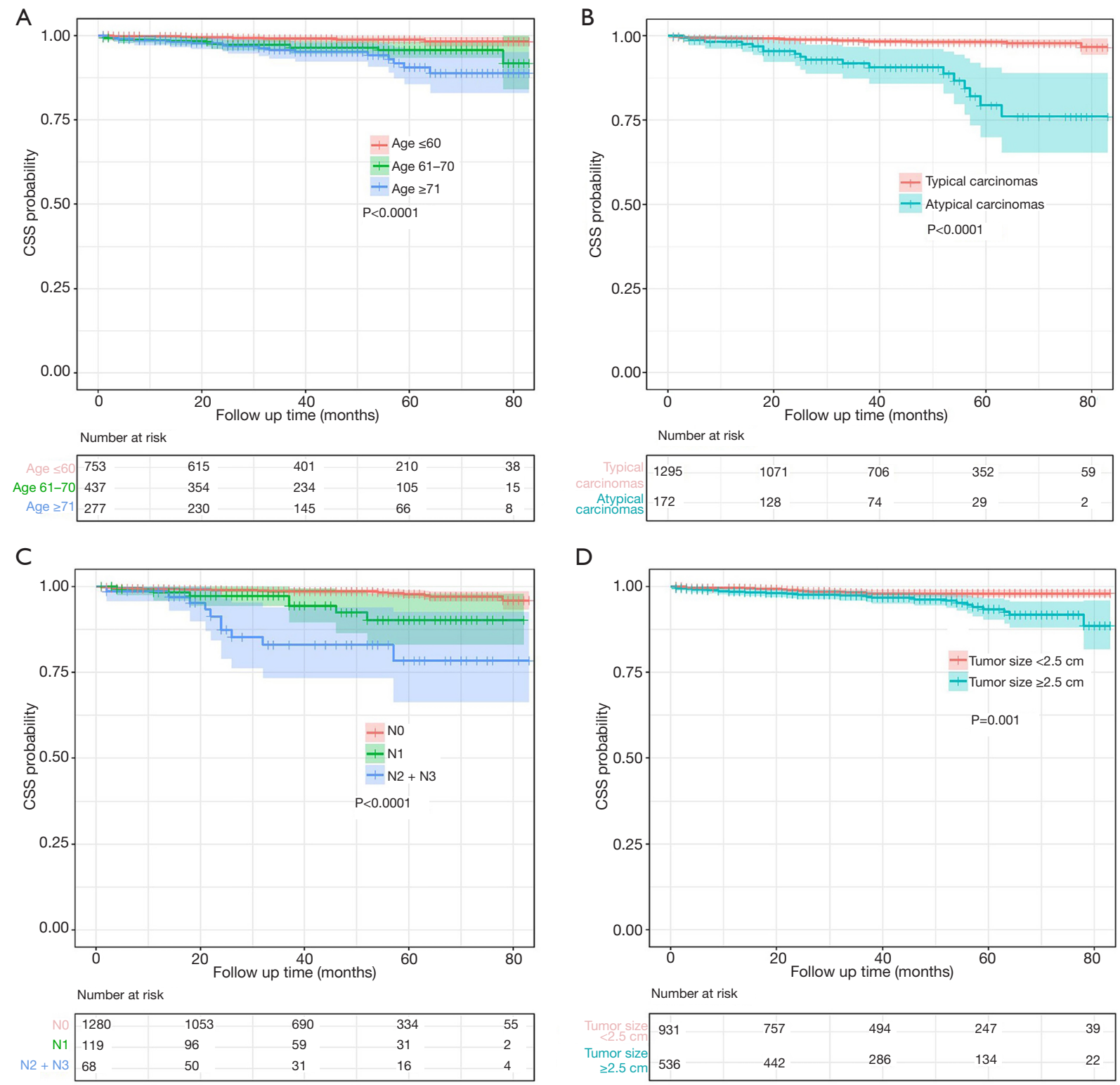

Figure 4 Cancer-specific survival analysis. (A) Age $\leq 60$ years $v s$. age $61-70 v s$. age $>70$ years. (B) Typical carcinoids vs. atypical carcinoids. (C) N0 stage $v s$. N1 stage $v s$. N2 + N3 stage. (D) Tumor size $<2.5 \mathrm{~cm} v s$. tumor size $\geq 2.5 \mathrm{~cm}$. CSS, cancer-specific survival.

prediction of the 1-, 3-, and 5-year OS in the nomogram model. Each variable was given a score on the points scale. By adding up the total scores shown in the bottom scale, the nomogram could predict the 1-, 3-, and 5-year OS for the individual patients. These factors were assigned specific scores as follows: age $\leq 60$ years, 0 ; age $61-70$ years, 152.23 ; age $>70$ years, 100 ; TCs, 0 ; ACs, 64.21; N0, $0 ; \mathrm{N} 1,50.44$; $\mathrm{N} 2+\mathrm{N} 3,81.64$. The total risk scores ranged from 0 to 298.08 for each patient based on the nomogram, and
$\mathrm{X}$-tile analysis was conducted to determine the optimal segmentation threshold for dividing patients into two subgroups: a high-risk group (total risk scores $>50.44$ ) and a low-risk group ( $0 \leq$ total risk scores $\leq 50.44)$. As shown in Figure 6A, the high-risk group exhibited significantly worse OS than the low-risk group $(\mathrm{P}<0.001)$. Calibration curves of each dataset were created for 1-, 3-, and 5-year OS (shown in Figure 7) and demonstrated good consistency between nomogram prediction and actual observation. 


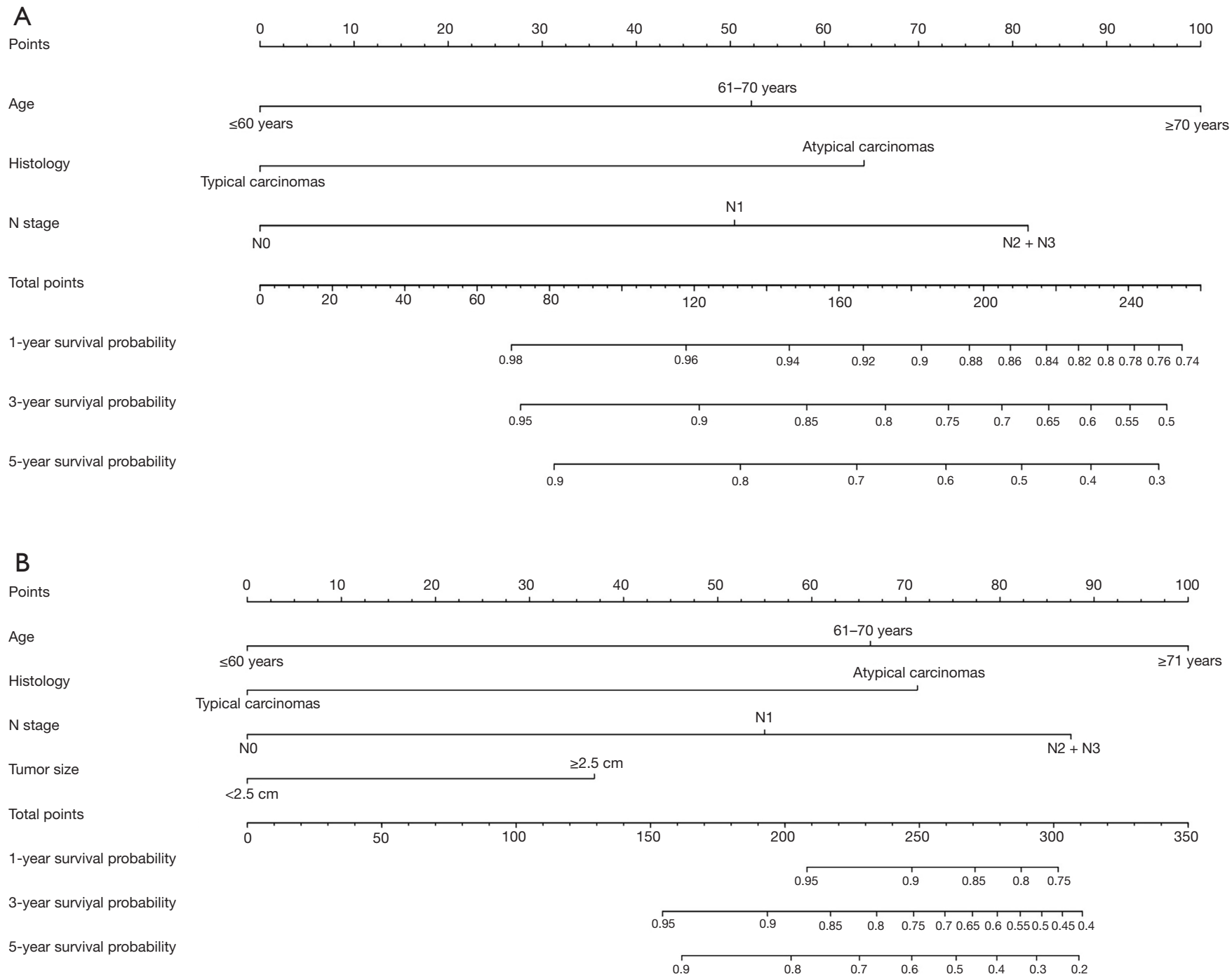

Figure 5 Nomogram for survival. (A) Nomogram for overall survival. (B) Nomogram for CSS. The sum of the scores for each variable is plotted on the total points axis; the estimated probabilities of overall survival at 1,3 and 5 years were obtained by drawing a line perpendicularly from the plotted total points axis straight to the survival axis.

The C-indexes of the training set, internal validation set, and external validation set were $0.718 \pm 0.029,0.661 \pm 0.097$, and $0.85 \pm 0.007$, respectively, indicating a preferable discriminatory ability.

The predictions of 1-, 3-, and 5-year CSS in the nomogram model was shown in Figure 5 B. Each variable had a score on the score scale. By adding the total scores shown in the underlying scale, the histogram could predict $1-, 3$-, and 5-year CSS for each patient. These factors were assigned specific scores as follows: age $\leq 60$ years, 0 ; age 61-70 years, 66.23; age $>70$ years, 100 ; TCs, 0 ; ACs, 71.23; tumor size $<2.5 \mathrm{~cm}, 0$; tumor size $\geq 2.5 \mathrm{~cm}, 36.90$; N0, 0; $\mathrm{N} 1,54.99 ; \mathrm{N} 2+\mathrm{N} 3,87.54$. The total risk scores ranged from 0 to 258.77 for each patient based on the nomogram, and $\mathrm{X}$-tile analysis was conducted to determine the optimal segmentation threshold for dividing patients into three subgroups (high-risk: 0-71.22, middle-risk: 71.23-100.00, and low-risk: 100.01-258.77) according to these total risk scores. As shown in Figure 6B, the high-risk group exhibited significantly worse OS than the middle-risk $(\mathrm{P}<0.001)$ and low-risk $(\mathrm{P}<0.001)$ groups. And the middle-risk group was associated with significantly worse OS than the low-risk 

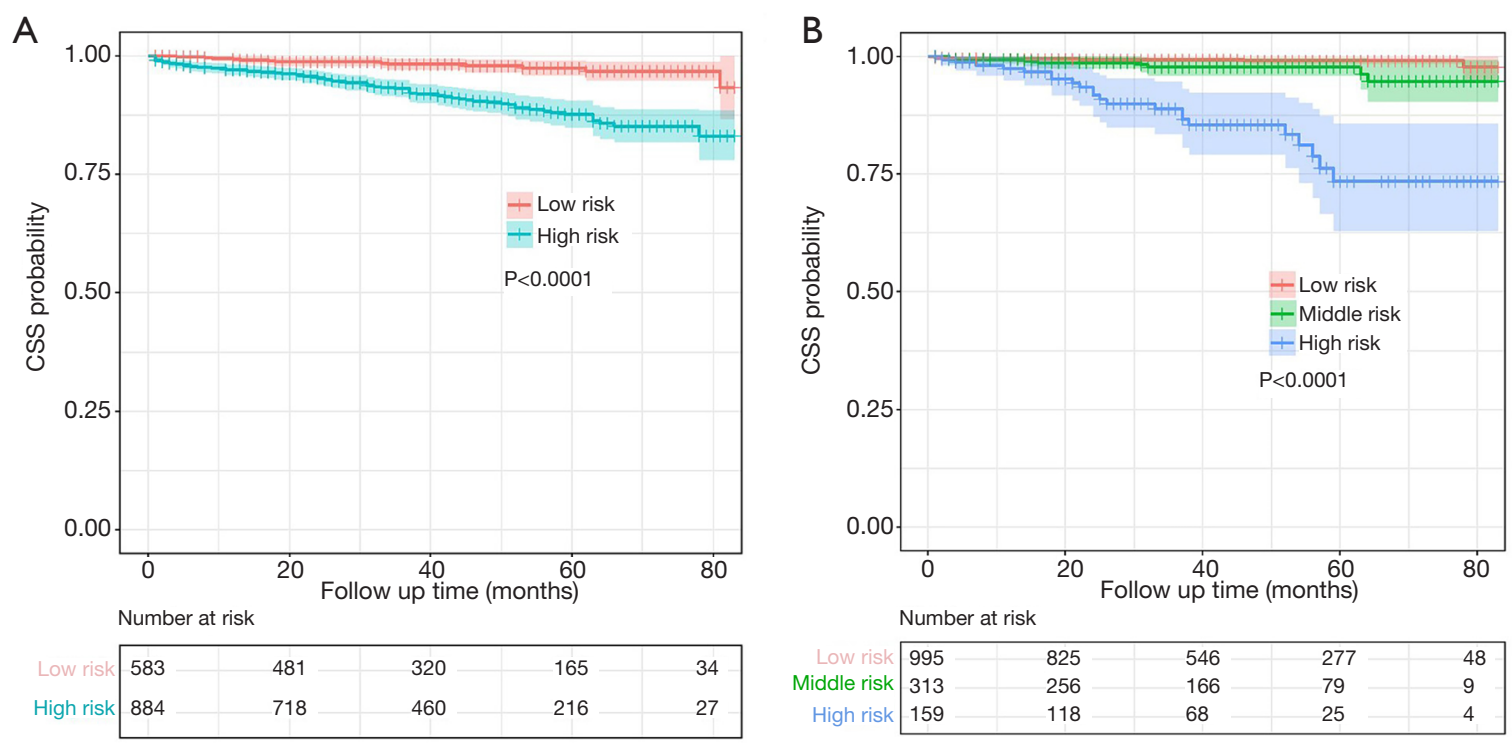

Figure 6 Overall survival (A) and cancer-specific survival (B) analysis of the different risk groups. OS, overall survival; CSS, cancer-specific survival.

group $(\mathrm{P}=0.018)$. Calibration curves of the training dataset and internal validation were created for 1-, 3-, and 5-year CSS (shown in Figure 8) and demonstrated good calibration between the predictions by the nomogram and the actual observations. The $\mathrm{C}$-indexes of the training set and internal validation set were $0.833 \pm 0.029$ and $0.756 \pm 0.149$, respectively, indicating a preferable discriminatory ability.

\section{Discussion}

We extracted a large number of BPC patients who underwent resection from a population-based database and established a nomogram based on independent prognostic factors to precisely predict long-term survival. The results of our study showed that age, pathological type, $\mathrm{N}$ grade, and tumor size were significant prognostic factors for BPCs. Favorable internal and external validation results were obtained from the C-index and calibration. The strengths of our study included the following aspects: first, our study was the first to establish nomograms for surgically resected BPC patients based on a large sample population; second, not only internal validation was clarified in the current study but also external validation sets were designed to validate our nomograms. Furthermore, clinicians can use our proposed nomograms to divide patients into subgroups according to their total risk scores, which helps them predict the prognoses of patients more intuitively and efficiently. Third, we established predictive models for OS and CSS to eliminate the influence of other comorbidities.

For BPC patients who underwent resection, one of the most important prognostic factors was age in the current study. Aging had a negative impact on the prognosis of patients, especially in patients older than 70 years. This result was consistent with the findings of other studies in which older age led to lower survival rates in cancer $(15,20)$. The reason may be that with age, patients may develop more comorbidities and become less tolerant to treatments such as surgery (21).

Multiple studies have demonstrated that histologic type was an equally stronger predictor of long-term prognosis than the TNM stage $(22,23)$. In our study, both the OS and CSS of the AC patients were worse than those of the TC patients, which may be related to their histologic nature. Mitotic count is a cornerstone of evaluating the proliferative activity in tumor cells (24). ACs have more mitoses $/ 2 \mathrm{~mm}^{2}$ than TCs, and a high mitotic count had been reported to be a disadvantage for survival in cancer patients because it indicates a higher proliferative activity of tumor cells $(11,15,25)$. Numerous studies have demonstrated that the performance of the Ki-67 index to differentially diagnose TC and AC was excellent (5,26-28), which was another indicator for evaluating the proliferation activity of tumor cells. A higher Ki-67 index in AC was one of the known adverse prognostic factors $(25,29)$. The presence of necrosis 
A

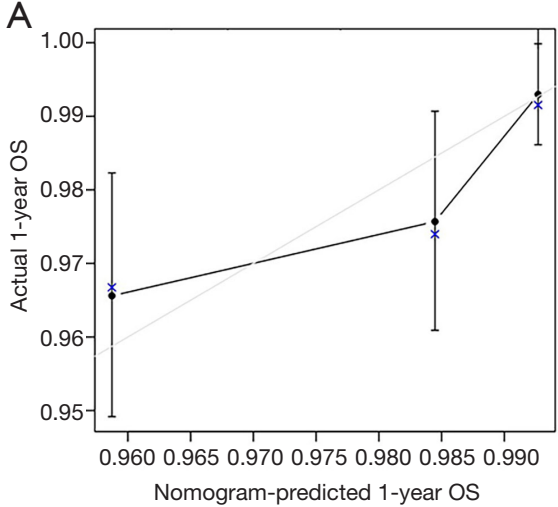

D

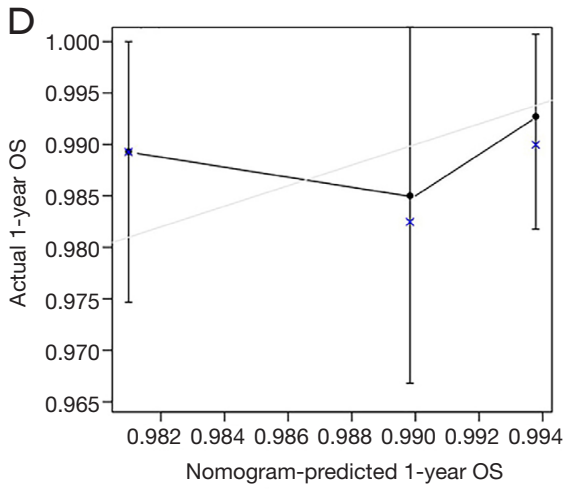

G

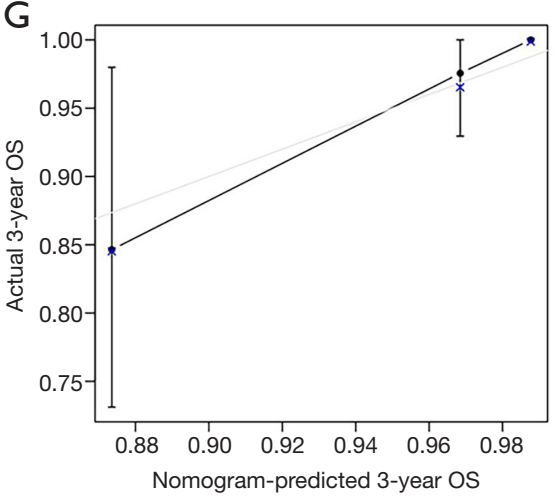

B

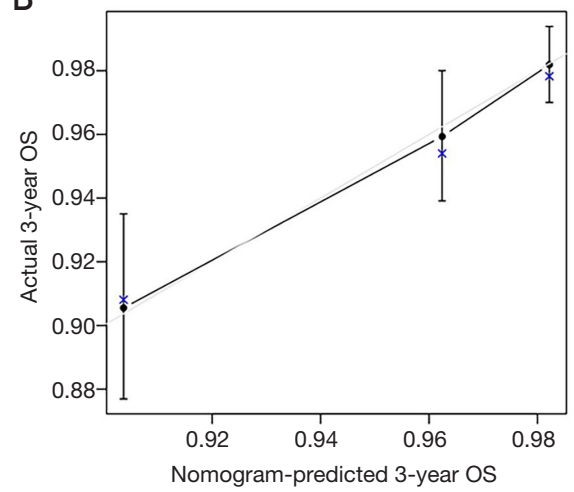

$\mathrm{E}$

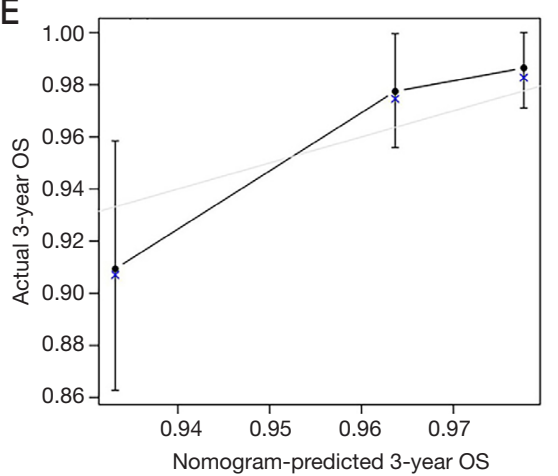

$\mathrm{H}$

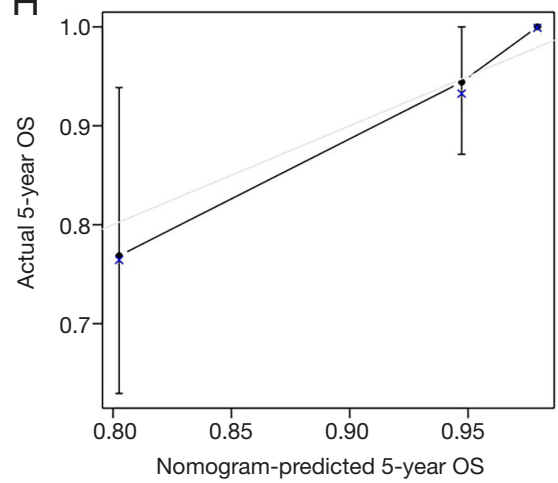

C

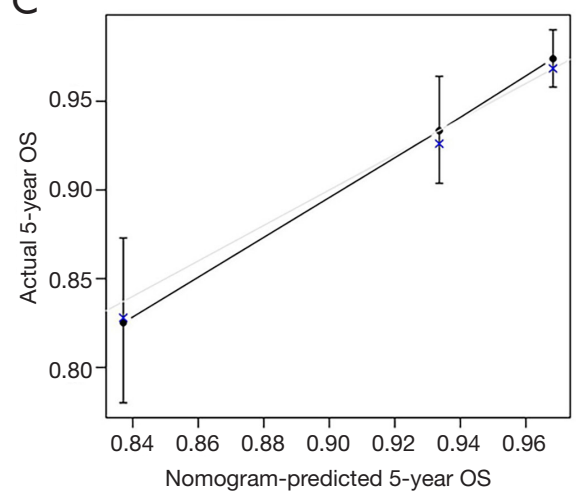

$\mathrm{F}$

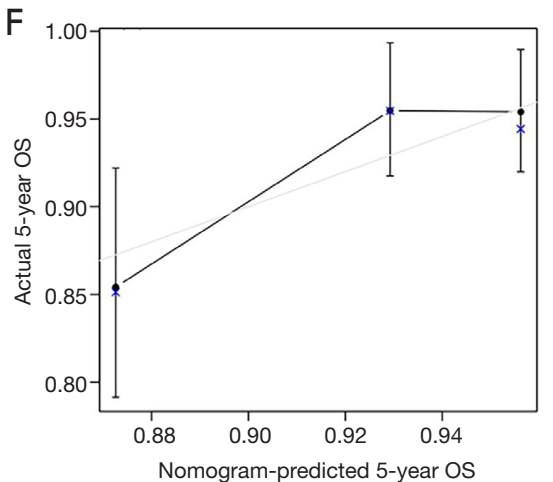

Figure 7 Calibration curves for predicting overall survival. Training dataset (A-C): 1-year overall survival (A), 3-year overall survival (B) and 5 -year overall survival (C). Internal validation dataset (D-F): 1-year overall survival L (D), 3-year overall survival (E) and 5-year overall survival (F). External validation dataset (G,H): 3-year overall survival $(\mathrm{G})$ and 5-year overall survival (H). OS, overall survival.

is another criterion for differentiating TC from AC. Necrosis was more common in ACs, and previous studies found that necrosis was significantly associated with tumor recurrence and survival $(11,25)$. In addition, some mutations of tumor-related genes are specifically enriched in ACs (30), such as FAIM2 and MEN1. Kang et al. (31) found that FAIM2 expression is significantly higher in ACs than in TCs. As an inhibitory molecule in the Fas-apoptosis pathway, FAIM2 inhibited anti-apoptotic molecules, which may restore repressed apoptosis signaling and eventually lead to tumor cell death.

$\mathrm{N}$ stage (AJCC, 7th ed.) was also taken into account when constructing models. Shorter OS and CSS were more common in patients with $\mathrm{N} 2$ or $\mathrm{N} 3$ stage, which indicated that lymph node involvement was significantly associated with prognosis. This is consistent with the results of many 
A

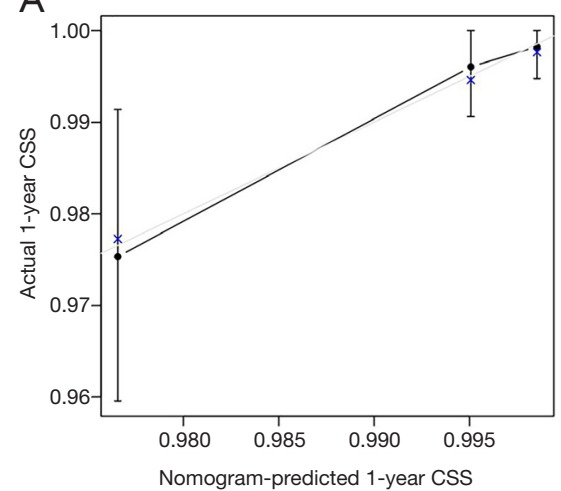

D

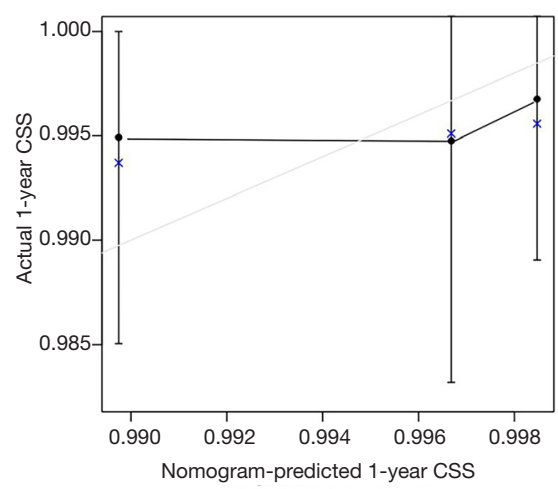

B

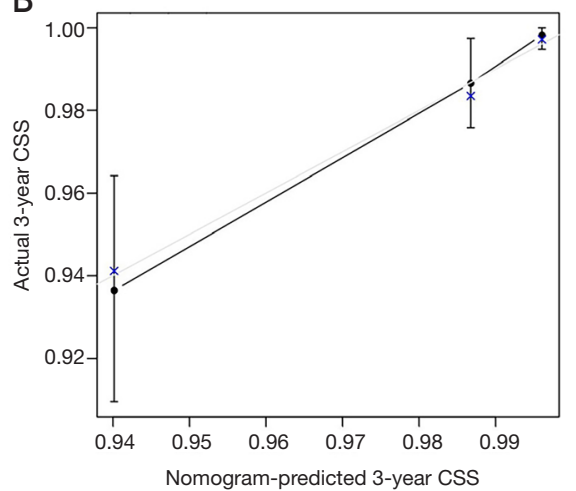

E

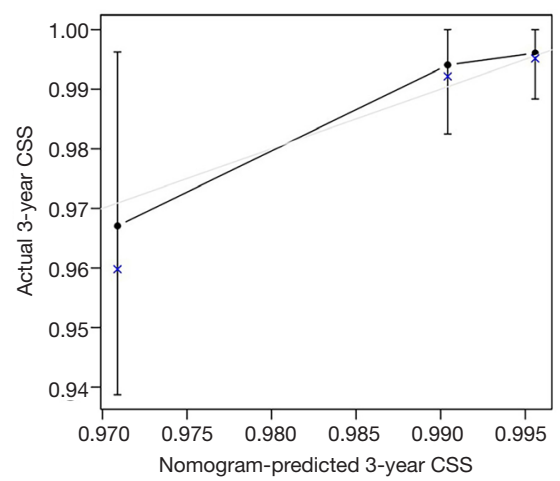

C

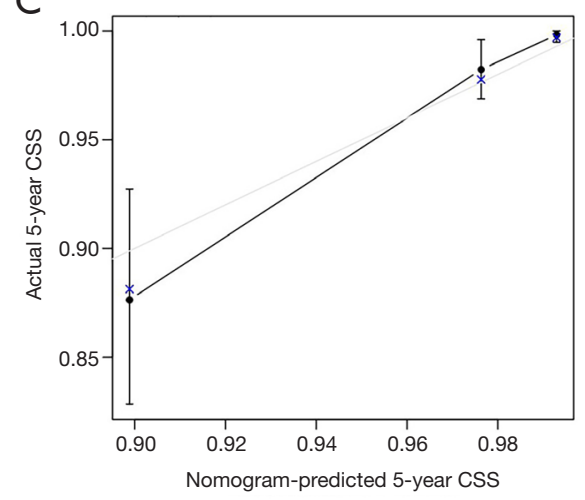

$\mathrm{F}$

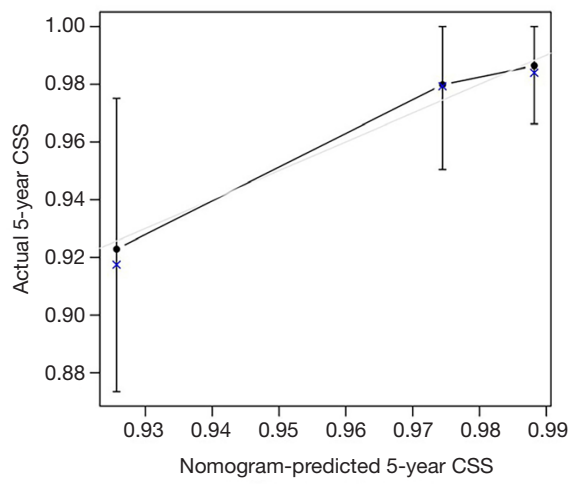

Figure 8 Calibration curves for predicting cancer-specific survival. Training dataset (A-C): 1-year cancer-specific survival (A), 3-year cancerspecific survival (B) and 5-year cancer-specific survival (C). Internal validation dataset (D-F): 1-year cancer-specific survival (D), 3-year cancer-specific survival (E) and 5-year cancer-specific survival (F). CSS, cancer-specific survival.

previous studies $(13,15,20,32,33)$. In addition, we also found that the proportion of AC patients with stage $\mathrm{N} 2+\mathrm{N} 3$ was significantly higher than that of TC patients $(\mathrm{P}<0.05)$. Previous studies have also proven that patients with ACs are characterized by a greater tendency to develop lymph nodal metastases and a worse prognosis $(7,14,34,35)$. The possible reason was that ACs show more aggressive biological behaviors than TCs $(11,36)$. Therefore, nodal classification is an important component of the tumor staging system, especially for treatment decision-making and prognosis prediction. The $\mathrm{N}$ stage of the seventh TNM staging system remained the same as in the previous version and depended solely on the anatomic extent of the involved lymph nodes (22). However, with mounting evidence tying the association between lymph node involvement and prognosis, some debatable questions remain for the location-based $\mathrm{N}$ stage. The most important factor was the prognostic heterogeneity of patients in the same $\mathrm{N}$ stage (37-39). Saji et al. demonstrated that the $\mathrm{N}$ stage based on the number of metastatic lymph nodes was a better prognostic determinant for bronchopulmonary NETs (33). Ding et al. proposed a potential revised $\mathrm{N}$ classification according to the combination of anatomical location and lymph node ratio that may provide a more precise prognosis (32). Other studies also developed similar new lymph node stage standards in other NETs, such as the gastrointestinal tract (40). These new $\mathrm{N}$ classifications may provide a more accurate prognosis than the location-based pathological $\mathrm{N}$ stage in terms of survival.

The TNM staging system was recognized as a predictor of prognosis and a basis for selecting treatment options among patients with lung carcinoid tumors $(13,22)$. However, our study failed to detect the predictive value of the $\mathrm{T}$ stage and $\mathrm{M}$ stage. This may account for the limitation of the data, but $\mathrm{He}$ et al. also found that the $\mathrm{T}$ stage had no predictive effect on prognosis (18). There was no doubt that we believe that the TNM system is essential for lung carcinoids. For the population in the current study, 
more predictive factors, such as age and pathological type, should be considered to construct the prognostic nomogram rather than the $\mathrm{T}$ or $\mathrm{M}$ stage to improve the accuracy of prediction.

Another variable associated with CSS in our study was tumor size. Based on a large sample of BPC patients who underwent surgical resection, this study explored the optimal cut-off value of tumor size by $\mathrm{X}$-tile. Tumor size $\geq 2.5 \mathrm{~cm}$ was significantly associated with poor CSS in patients. Previous studies have indicated that as one of the local anatomical factors, tumor size had a great influence on the prognosis of lung tumors $(15,18)$. Compared with the seventh edition of the TNM staging system, the most significant change in the eighth edition was the decrease in tumor size (13). In other words, a tumor of a certain size may relate to higher risk in the eighth edition of the TNM staging system, indicating to some extent that the effect of tumor size on staging and prognosis is increasingly valued.

Surgery remains the cornerstone of treatment for BPCs to remove the tumor and preserve as much lung tissue as possible (5), which was related to better longterm survival in previous studies $(8,16,18,41)$. Lobectomy is the most commonly performed procedure $(11,41)$, which is consistent with our research. In the univariate analysis of this study, patients who underwent lobectomy had better OS than those who underwent other surgical procedures. However, in multivariate analysis, the choice of surgical procedure was not an independent predictive factor for survival. There was no consensus on the choice of surgical procedure. Daskalakis et al. (16) suggested that a more conservative surgical approach with formal anatomical resection had a better survival benefit than more extensive procedures. Reuling et al. (10) suggested that small located intraluminal BPCs without signs of metastasis can be treated with minimally invasive alternatives such as endobronchial treatment or parenchyma sparing surgical resection. Therefore, individualized treatment and selection of patients who can benefit from surgical procedures are very important.

The role of chemotherapy in BPCs is controversial. In our study, chemotherapy was not an independent diagnostic factor for BPCs, but in univariate analyses, chemotherapy was shown to have negative effects on OS and CSS. In population-based studies and retrospective studies, no survival advantage of chemotherapy was observed for patients with TCs or ACs (42-44). Based on the above studies, chemotherapy was not recommended as a routine treatment. However, it is still necessary to explore the utility of chemotherapy in prospective studies with larger cohorts.

Several limitations in the current study should be noted. First, the variables used to build the nomograms only represented some of the clinicopathological characteristics. The absence of some crucial variables, such as the Ki67 index (25) and chromogranin A (4), may reduce the accuracy of our prognostic models. These will be the main directions of future researches. Second, our nomograms were established based on a retrospective cohort study. Even though they showed good discrimination and validation, further validation in larger-scale external cohorts is needed. Third, owing to the limitations of the SEER database, only the seventh edition of the TNM stage records were extracted. Some studies have proven that TNM 8th edition was a more accurate predictor of outcomes than the 7 th edition in BPCs $(13,22)$. And we unable to obtain the smoking status of patients. Despite these limitations, our prognostic nomograms are important and effective models for providing accurate and individualized survival predictions in BPC patients.

To conclude, we found independent prognostic factors for the survival of BPC patients receiving resection and established nomograms based on the SEER database. The nomograms were evaluated in both an internal validation SEER dataset and an external validation dataset, which displayed favorable prognostic discrimination and accuracy of prediction of OS and CSS. These nomograms can provide a basis for clinicians to make individualized clinical decisions and guide follow-up management strategies for BPC patients receiving resection.

\section{Acknowledgments}

We would like to thank "AJE editing service" for their help in polishing our paper.

Funding: This study was supported by the State Key Project on Infection Diseases of China (Grant number. 2017ZX10201021-007-003), the National capital health research and development of special (Grant number. 20181-4021), the National Natural Science Foundation of China (Grant number. 81672461, 81972311), the CAMS Innovation Fund for Medical Sciences (CIFMS) (Grant number. 2017-12M-4-002), the Non-profit Central Research Institution Fund of Chinese Academy of Medical Sciences (Grant number. 2019PT310026), and the Sanming Project of Medicine in Shenzhen (Grant number. 
SZSM202011010).

\section{Footnote}

Reporting Checklist: The authors have completed the TRIPOD reporting checklist. Available at https://dx.doi. org/10.21037/atm-21-1929

Peer Review File: Available at https://dx.doi.org/10.21037/ atm-21-1929

Conflicts of Interest: All authors have completed the ICMJE uniform disclosure form (available at https://dx.doi. org/10.21037/atm-21-1929). The authors have no conflicts of interest to declare.

Ethical Statement: The authors are accountable for all aspects of the work in ensuring that questions related to the accuracy or integrity of any part of the work are appropriately investigated and resolved. The study was conducted in accordance with the Declaration of Helsinki (as revised in 2013). The study was approved by Institutional Review Board of the Cancer Institute \& Hospital, Chinese Academy of Medical Sciences (ethical approval number: NCC-006062) and informed consent was taken from all the patients.

Open Access Statement: This is an Open Access article distributed in accordance with the Creative Commons Attribution-NonCommercial-NoDerivs 4.0 International License (CC BY-NC-ND 4.0), which permits the noncommercial replication and distribution of the article with the strict proviso that no changes or edits are made and the original work is properly cited (including links to both the formal publication through the relevant DOI and the license). See: https://creativecommons.org/licenses/by-nc-nd/4.0/.

\section{References}

1. Yao JC, Hassan M, Phan A, et al. One hundred years after "carcinoid": epidemiology of and prognostic factors for neuroendocrine tumors in 35,825 cases in the United States. J Clin Oncol 2008;26:3063-72.

2. Dasari A, Shen C, Halperin D, et al. Trends in the Incidence, Prevalence, and Survival Outcomes in Patients With Neuroendocrine Tumors in the United States. JAMA Oncol 2017;3:1335-42.

3. Naalsund A, Rostad H, Strøm EH, et al. Carcinoid lung tumors--incidence, treatment and outcomes: a populationbased study. Eur J Cardiothorac Surg 2011;39:565-9.

4. Baudin E, Caplin M, Garcia-Carbonero R, et al. Lung and thymic carcinoids: ESMO Clinical Practice Guidelines for diagnosis, treatment and follow-up $\boldsymbol{s}^{-}$. Ann Oncol 2021;32:439-51.

5. Caplin ME, Baudin E, Ferolla P, et al. Pulmonary neuroendocrine (carcinoid) tumors: European Neuroendocrine Tumor Society expert consensus and recommendations for best practice for typical and atypical pulmonary carcinoids. Ann Oncol 2015;26:1604-20.

6. Travis WD, Brambilla E, Nicholson AG, et al. The 2015 World Health Organization Classification of Lung Tumors: Impact of Genetic, Clinical and Radiologic Advances Since the 2004 Classification. J Thorac Oncol 2015;10:1243-60.

7. Papaporfyriou A, Domayer J, Meilinger M, et al. Bronchoscopic diagnosis and treatment of endobronchial carcinoid: case report and review of the literature. Eur Respir Rev 2021;30:200115.

8. Huang Y, Yang X, Lu T, et al. Assessment of the prognostic factors in patients with pulmonary carcinoid tumor: a population-based study. Cancer Med 2018;7:2434-41.

9. Petursdottir A, Sigurdardottir J, Fridriksson BM, et al. Pulmonary carcinoid tumours: incidence, histology, and surgical outcome. A population-based study. Gen Thorac Cardiovasc Surg 2020;68:523-9.

10. Reuling EMBP, Dickhoff C, Plaisier PW, et al. Endobronchial and surgical treatment of pulmonary carcinoid tumors: A systematic literature review. Lung Cancer 2019;134:85-95.

11. Tsuta K, Raso MG, Kalhor N, et al. Histologic features of low- and intermediate-grade neuroendocrine carcinoma (typical and atypical carcinoid tumors) of the lung. Lung Cancer 2011;71:34-41.

12. Phan AT, Oberg K, Choi J, et al. NANETS consensus guideline for the diagnosis and management of neuroendocrine tumors: well-differentiated neuroendocrine tumors of the thorax (includes lung and thymus). Pancreas 2010;39:784-98.

13. Yoon JY, Sigel K, Martin J, et al. Evaluation of the Prognostic Significance of TNM Staging Guidelines in Lung Carcinoid Tumors. J Thorac Oncol 2019;14:184-92.

14. Filosso PL, Oliaro A, Ruffini E, et al. Outcome and prognostic factors in bronchial carcinoids: a single-center experience. J Thorac Oncol 2013;8:1282-8.

15. Moran CA, Lindholm KE, Brunnström H, et al.

Typical and atypical carcinoid tumors of the lung: a 
clinicopathological correlation of 783 cases with emphasis on histological features. Hum Pathol 2020;98:98-109.

16. Daskalakis K, Kaltsas G, Öberg K, et al. Lung Carcinoids: Long-Term Surgical Results and the Lack of Prognostic Value of Somatostatin Receptors and Other Novel Immunohistochemical Markers. Neuroendocrinology 2018;107:355-65.

17. Chen X, Pang Z, Wang Y, et al. The role of surgery for atypical bronchopulmonary carcinoid tumor: Development and validation of a model based on Surveillance, Epidemiology, and End Results (SEER) database. Lung Cancer 2020;139:94-102.

18. He Y, Zhao F, Han Q, et al. Prognostic nomogram for predicting long-term cancer-specific survival in patients with lung carcinoid tumors. BMC Cancer 2021;21:141.

19. Institute NC. Surveillance, Epidemiology, and End Results (SEER). Available online: http://www.seer.cancer.gov

20. Georgakopoulou VE, Zygouris E, Nikokiris C, et al. Predictive Indicators of Survival in Patients With Surgically Resected Lung Carcinoid Tumors at a Greek Medical Center. Cureus 2020;12:e10300.

21. Iijima $Y$, Iwai S, Yamagata A, et al. Is lung resection appropriate for late octogenarians? Surgical outcomes of patients aged $\geq 80$ years with lung cancer. Clin Transl Oncol 2021;23:1585-92.

22. Dermawan JK, Farver CF. The Prognostic Significance of the 8th Edition TNM Staging of Pulmonary Carcinoid Tumors: A Single Institution Study With Long-term Follow-up. Am J Surg Pathol 2019;43:1291-6.

23. Song $\mathrm{P}$, Zang R, Liu L, et al. Long-term outcomes and prognostic factors of patients with surgically treated pulmonary atypical carcinoid tumors: our institutional experience with 68 patients. J Thorac Dis 2018;10:4204-11.

24. Warth A, Fink L, Fisseler-Eckhoff A, et al. Interobserver agreement of proliferation index (Ki-67) outperforms mitotic count in pulmonary carcinoids. Virchows Arch 2013;462:507-13

25. Clay V, Papaxoinis G, Sanderson B, et al. Evaluation of diagnostic and prognostic significance of $\mathrm{Ki}-67$ index in pulmonary carcinoid tumours. Clin Transl Oncol 2017;19:579-86.

26. Zahel T, Krysa S, Herpel E, et al. Phenotyping of pulmonary carcinoids and a Ki-67-based grading approach. Virchows Arch 2012;460:299-308.

27. Swarts DR, van Suylen RJ, den Bakker MA, et al. Interobserver variability for the $\mathrm{WHO}$ classification of pulmonary carcinoids. Am J Surg Pathol 2014;38:1429-36.

28. Pelosi G, Sonzogni A, Harari S, et al. Classification of pulmonary neuroendocrine tumors: new insights. Transl Lung Cancer Res 2017;6:513-29.

29. Moris D, Ntanasis-Stathopoulos I, Tsilimigras DI, et al. Insights into Novel Prognostic and Possible Predictive Biomarkers of Lung Neuroendocrine Tumors. Cancer Genomics Proteomics 2018;15:153-63.

30. Simbolo M, Mafficini A, Sikora KO, et al. Lung neuroendocrine tumours: deep sequencing of the four World Health Organization histotypes reveals chromatinremodelling genes as major players and a prognostic role for TERT, RB1, MEN1 and KMT2D. J Pathol 2017;241:488-500.

31. Kang HC, Kim JI, Chang HK, et al. FAIM2, as a novel diagnostic maker and a potential therapeutic target for small-cell lung cancer and atypical carcinoid. Sci Rep 2016;6:34022.

32. Ding X, Hui Z, Dai H, et al. A Proposal for Combination of Lymph Node Ratio and Anatomic Location of Involved Lymph Nodes for Nodal Classification in Non-Small Cell Lung Cancer. J Thorac Oncol 2016;11:1565-73.

33. Saji H, Tsuboi M, Shimada Y, et al. A proposal for combination of total number and anatomical location of involved lymph nodes for nodal classification in non-small cell lung cancer. Chest 2013;143:1618-25.

34. García-Yuste M, Matilla JM, Cueto A, et al. Typical and atypical carcinoid tumours: analysis of the experience of the Spanish Multi-centric Study of Neuroendocrine Tumours of the Lung. Eur J Cardiothorac Surg 2007;31:192-7.

35. Prinzi N, Rossi RE, Proto C, et al. Recent Advances in the Management of Typical and Atypical Lung Carcinoids. Clin Lung Cancer 2021;22:161-9.

36. Fink G, Krelbaum T, Yellin A, et al. Pulmonary carcinoid: presentation, diagnosis, and outcome iN142 cases in Israel and review of 640 cases from the literature. Chest 2001;119:1647-51.

37. Nwogu CE, Groman A, Fahey D, et al. Number of lymph nodes and metastatic lymph node ratio are associated with survival in lung cancer. Ann Thorac Surg 2012;93:1614-9; discussioN1619-20.

38. Saji H, Tsuboi M, Yoshida K, et al. Prognostic impact of number of resected and involved lymph nodes at complete resection on survival in non-small cell lung cancer. J Thorac Oncol 2011;6:1865-71.

39. Xu L, Su H, She Y, et al. Which N Descriptor Is More Predictive of Prognosis in Resected Non-small Cell Lung Cancer: The Number of Involved Nodal Stations or the Location-Based Pathological N Stage? Chest 2021;159:2458-69. 
40. Li J, Lin Y, Wang Y, et al. Prognostic nomogram based on the metastatic lymph node ratio for gastric neuroendocrine tumour: SEER database analysis. ESMO Open 2020;5:e000632.

41. Dong S, Liang J, Zhai W, et al. Development and Validation of an Individualized Nomogram for Predicting Overall Survival in Patients With Typical Lung Carcinoid Tumors. Am J Clin Oncol 2020;43:607-14.

42. Nussbaum DP, Speicher PJ, Gulack BC, et al. Defining the role of adjuvant chemotherapy after lobectomy for typical

Cite this article as: Li Q, Chen Q, Chen J, Wang Z, Wang P, Zhao H, Zhao J. Prognostic nomogram for predicting longterm survival in bronchopulmonary carcinoid tumor patients receiving resection. Ann Transl Med 2021;9(18):1402. doi: 10.21037/atm-21-1929 bronchopulmonary carcinoid tumors. Ann Thorac Surg 2015;99:428-34.

43. Anderson KL Jr, Mulvihill MS, Speicher PJ, et al. Adjuvant Chemotherapy Does Not Confer Superior Survival in Patients With Atypical Carcinoid Tumors. Ann Thorac Surg 2017;104:1221-30.

44. Filosso PL, Ferolla P, Guerrera F, et al. Multidisciplinary management of advanced lung neuroendocrine tumors. J Thorac Dis 2015;7:S163-71. 